\title{
PCR and Microscopic Identification of Isolated Leishmania tropica from Clinical Samples of Cutaneous Leishmaniasis in Human Population of Kohat Region in Khyber Pakhtunkhwa
}

\author{
Nasser M. Abd El-Salam, ${ }^{1}$ Sultan Ayaz, ${ }^{2}$ and Riaz Ullah ${ }^{3}$ \\ ${ }^{1}$ Arriyadh Community College, King Saud University, P.O. Box 28095, Riyadh 11437, Saudi Arabia \\ ${ }^{2}$ Department of Zoology, Kohat University of Science and Technology, Kohat 26000, Pakistan \\ ${ }^{3}$ Department of Chemistry, Government College Ara Khel, FR Kohat, Khyber Pakhtunkhwa 26000, Pakistan
}

Correspondence should be addressed to Riaz Ullah; afridiriaz@yahoo.com

Received 6 January 2014; Revised 16 February 2014; Accepted 16 February 2014; Published 1 April 2014

Academic Editor: Terry K. Smith

Copyright (C) 2014 Nasser M. Abd El-Salam et al. This is an open access article distributed under the Creative Commons Attribution License, which permits unrestricted use, distribution, and reproduction in any medium, provided the original work is properly cited.

Leishmania tropica was isolated from the clinical patients of cutaneous leishmaniasis in rural community of Kohat district in Khyber Pakhtunkhwa province and was identified through PCR, microscopy, and culture techniques. A total of 113 samples from the clinical patients were examined through PCR, microscopy, and culture which showed 87.61\% (99/113), 53.98\% (61/113), and 46.90\% (53/113) prevalence. During the study, 186 bp Leishmania tropica was identified through PCR. Thus the sensitivity of PCR is very high as compared to the conventional techniques.

\section{Introduction}

Leishmaniasis is a disease caused by Leishmania parasite and transmitted to mammals and human beings by Phlebotomine sand flies and it causes skin infections [1,2]. Twenty-one species of Leishmania have been reported to cause human infection [1]. Each year, 1.5-2 million new cases are reported and 70,000 deaths occurred. The number of disease and death cases showed about 2.4 million people affected throughout the world [3]. Leishmaniasis can produce various symptoms in mammalian host depending on the host genetic makeup and species of the Leishmania parasite [4].

Approximately, $90 \%$ of the cases of the cutaneous leishmaniasis were observed in Iran, Afghanistan, Pakistan, Saudi Arabia, Brazil, Peru, and Syria [5]. Cutaneous leishmaniasis is a common infection that is endemic in many regions of Pakistan [6-8]. It is not a cause of mortality but can cause morbidity and social isolation due to its disfiguring complications. The lesions are mostly found on the exposed areas of the skin $[6,9,10]$. The lesion or ulcer leaves a scar on infected area [11]. Secondary bacterial or fungal infection of the ulcers causes increased tissue destruction and disfiguring of the skin [9].

Several techniques have been described for the identification of Leishmania at the molecular level. These techniques include sequence analysis of multicopy genes, restriction fragment length polymorphism, inter genic spacer regions, DNA fingerprinting, polymerase chain reaction (PCR), and randomly amplified polymorphic DNA [12-15].

The accurate identification and diagnosis which are concerned with epidemiology, clinical finding, and management and treatment of the patient must be based on molecular diagnosis. Among these multilocus enzyme electrophoresis and cytochrome B gene sequencing is the gold slandered for diagnosis and identification; however, DNA based techniques are being used frequently. The PCR and sequencing of cytochrome B gene were established for species identification [16]. Many studies have been conducted in Pakistan where the main causative agents in southern dry area were Leishmania major and Leishmania tropica [17].

A comprehensive need assessment is required to devise public health strategies for an effective prevention of this 
rapidly spreading infection, particularly in the Khyber Pakhtunkhwa. Observing the gravity of the situation where many cases of skin ulcers and nonhealing lesion were diagnosed as cutaneous leishmaniasis in the local Pakistani community [18]. Keeping in view the importance and health hazard of the disease, the present research was designed to focus on the isolation and identification of the local strain of cutaneous leishmaniasis infecting the population of the present community and to compare conventional and PCR methods in detection of cutaneous leishmaniasis.

\section{Materials and Methods}

2.1. Area of Intervention. Samples were collected from the lesions of a patient with clinical suspected cutaneous leishmaniasis in rural communities in Kohat region of Khyber Pakhtunkhwa province (Figure 1). It is located at $33^{\circ} 35^{\prime} 13 \mathrm{~N}$, $71^{\circ} 26^{\prime} 29 \mathrm{E}$ with an altitude of about 489 meters above sea level and the total area is 2973 kilometers having population of 562640 individuals with an annual growth rate of $3.26 \%$. The climate of the area is usually dry, extremely hot in summer and extremely cold and dry in winter. The average rainfall is about $400 \mathrm{~mm}$. The Kohat region hosted more than 5 million IDPs in 2010, who migrated from military operated areas of tribal belt and Afghan refugees camp operating from the year 1981, which were the main source of CL migration from Afghanistan to the areas. The study was carried out from October 2010 to June 2011.

2.2. Sample Collection. Specimens were collected from Leishmania infected patients of cutaneous leishmaniasis. These lesions were cleaned with $70 \%$ alcohol. The skin scrapings were made with the help of scalpel in one direction till oozing out of the blood from the lesion and an incision was given mostly in the inflamed border of lesion. A smear of dermal tissue scrapings was collected from each patient. The smear samples were prepared and stained with Giemsa and then were seen under the microscope $(100 \mathrm{x})$ for presence of amastigote and the rest of the scraping samples were mixed with buffer at pH 7.2 and kept in sterile Eppendorf tube for future processes.

2.3. Cultivation and Isolation of Parasite. The culture medium RPMI-64 (Gibco, USA) was prepared for the purpose of the culturing of the Leishmania parasite from the samples. We dissolved the $0.3 \mathrm{~g} / 30 \mathrm{~mL}$ of medium RPMI-64 in distilled water $(10.43 \mathrm{~g} / 1000 \mathrm{~mL}$ of distilled water) and distributed it amongst the 10 vials of bijou bottle, each having $3 \mathrm{~mL}$ of the dissolved media with supplemented $10 \%$ fetal bovine serum. The antibiotic consisting of penicillin $\mathrm{G}$ and kanamycin were mixed in cultural media to avoid bacterial contamination. The bijou bottles were placed in ice jar and were taken to the field where we collect the samples from the identified suspected person. The skin scrapings were directly mixed from the lesion to each bottle in ice jar and transported to the Department Lab of Kohat University of Science and Technology, Kohat. Then the medium was incubated at $26^{\circ} \mathrm{C}$ in incubator (Memmert Type INB500, Germany) and was

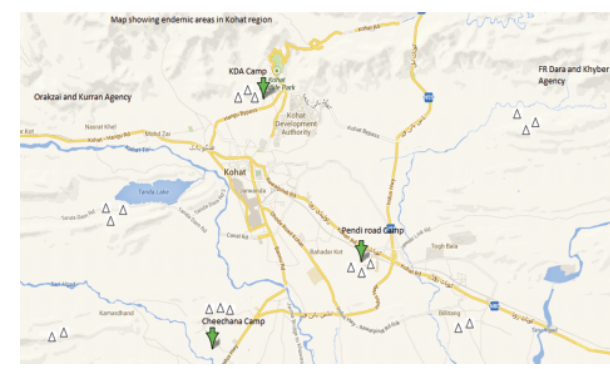

Figure 1

TABLE 1: Comparative detection of Leishmania in culture, direct microscopy, and PCR $n=113$.

\begin{tabular}{lccc}
\hline Sample & Culture & Microscopy & PCR \\
\hline Positive & 53 & 61 & 99 \\
Negative & 60 & 52 & 14 \\
Positive control & + & + & + \\
Negative control & - & - & - \\
\hline
\end{tabular}

examined at the different life stages of Leishmania tropica and was identified under 100x magnification of microscope for every 24 hours till up to 10 days.

2.4. DNA Extraction. The samples were subjected to DNA extraction by using GF-1 kit (Vivantis) as per the manufacturer protocol and extracted DNA were stored at $-86^{\circ} \mathrm{C}$ for further process.

2.5. DNA Amplification. For detection of leishmania parasites, PCR was performed. A reaction mixture was prepared containing $5 \mu \mathrm{L}$ buffer (10X PCR buffer), dNTPs $5 \mu \mathrm{L}$ $(500 \mu \mathrm{M}), \mathrm{MgCl}_{2}(25 \mu \mathrm{m}), 5 \mu \mathrm{L}$ Primers (Forward 5-TTTCTTGGATGGGTTTCTGG-3 and Reverse 3-CAACACCAACGTAAGCGTAAC-3 of kDNA region), target DNA $5 \mu \mathrm{L}, 0.3$ uni of taq. DNA polymerase and add deionized water up to $50 \mu \mathrm{L}$. After an initial denaturation at $92^{\circ} \mathrm{C}$ for 3 minutes. PCR was performed with 35 cycles of denaturation $\left(92^{\circ} \mathrm{C}, 1\right.$ minute), annealing $50^{\circ} \mathrm{C}$ and polymerization at $\left(72^{\circ} \mathrm{C}, 1\right.$ minute). In the last stage extension at $72^{\circ} \mathrm{C}$ for $7 \mathrm{~min}$ and holding at $4^{\circ} \mathrm{C}$ for unlimited time, the designed program was saved as CL PCR.

2.6. Gel Electrophoreses. $10 \mu \mathrm{L}$ of PCR product mixture was mixed with $5 \mu \mathrm{L}$ loading dye and loaded in a gel and $0.5 \mu \mathrm{L}$ ethidium bromide was added and poured into gel tray and combs were fixed. Combs were removed after gel was formed. Gel tray was placed in gel tank containing $1000 \mathrm{~mL}$ 0.5X TBE buffer. $15 \mu \mathrm{L}$ of each sample was loaded in the wells and $15 \mu \mathrm{L}$ of DNA ladder (100 bp) in separate well. The gel was run for $25 \mathrm{~min}$ at voltage of 120 volts and 500 ampere current. Gel was then examined by UV transilluminator. 
TABLE 2: Days detected for observation of promastigotes in the culture media of RPMI-1640 from suspected lesions.

\begin{tabular}{lcccccccccccc}
\hline Media & 1st day & 2nd day & 3rd day & 4th day & 5th day & 6th day & 7th day & 8th day & 9th day & 10th day & 11th day & 12th day \\
\hline RPMI 1640 & - & - & - & + & + & + & + & ++ & ++ & ++ & + & + \\
Negative control & - & - & - & - & - & - & - & - & - & - & - & - \\
\hline
\end{tabular}

$(-)$ indicates amastigote.

$(+)$ indicates promastigotes.

$(++)$ indicates promastigotes at peak level.

2.7. Sensitivity and Specificity of Diagnostic Techniques. The sensitivity and specificity of PCR, microscopy, and culture technique were calculated by the following methods:

\section{Sensitivity}

$$
=\frac{\text { No. of True Positive }}{\text { No. of True Positive }+ \text { No. of False Negative }},
$$

Specificity

$$
=\frac{\text { No. of True Negative }}{\text { No. of True Negative }+ \text { No. of False Positive }} .
$$

\section{Results and Discussion}

The productivity and the potential isolation of Leishmania amastigotes in RPMI-1640 media were assessed during the present study for evaluating the efficiency in the diagnosis and identification of the promastigotes and other life stages of the parasite. Leishmania samples were obtained from ten different suspected lesions of the patients. It was observed that the parasites were produced in seven bijou cultural bottles of RPMI-1640 media except in the three culture bottles. The results of cultivation, microscopic examination, and PCR of the materials were obtained from the patients having suspected CL lesions (Tables 1 and 2).

No amastigote was observed in the other three cultural bottles of the suspected lesions. RPMI-1640 media used in our studies have successful results either in isolation from suspected lesion or at the stage of diagnosis in patients. Amastigotes were in the first 1-5 days in the cultural media while promastigotes were seen up to 12 days; it was also observed that the highest level of production was seen in 9 and 10 days and it was determined that no growth existed in control bottles of the media (Figures 2 and 3). The results obtained from the two assays (microscopy and PCR) (Figures 4 and 5) for Leishmania were analyzed which showed some correlation between the two assays. The PCR sensitivity was $87.61 \%(99 / 113)$ of the total tested samples while the microscopy showed the $53.98 \%$ (61/113) sensitivity. Microscopy was positive in 61 samples for amastigotes of Leishmania presence as compared to PCR which detected kDNA of L. tropica in 99 samples, while culture showed $46.90 \%$ (53/113); thus the sensitivity of PCR is very high as compared to microscopy and culture. Microscopy and culture have poor sensitivity for low amastigotes in the field while PCR can amplify a single amastigotes if present and PCR was more specific than microscopy in terms of diagnosis (Table 3 ).

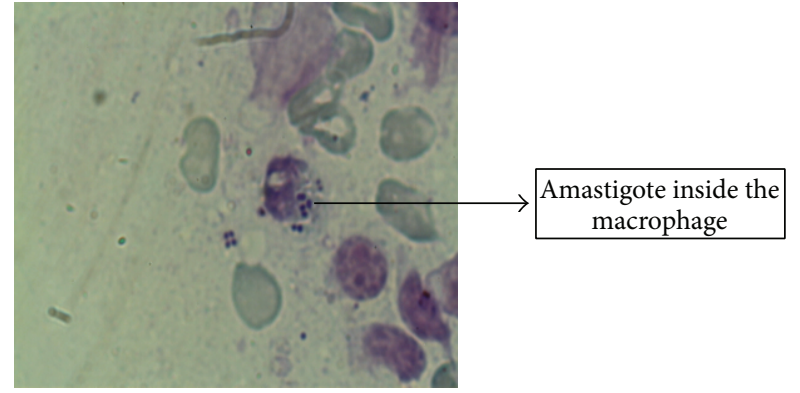

FIgURE 2: Giemsa stain image showing the amastigote form of Leishmania inside macrophages.

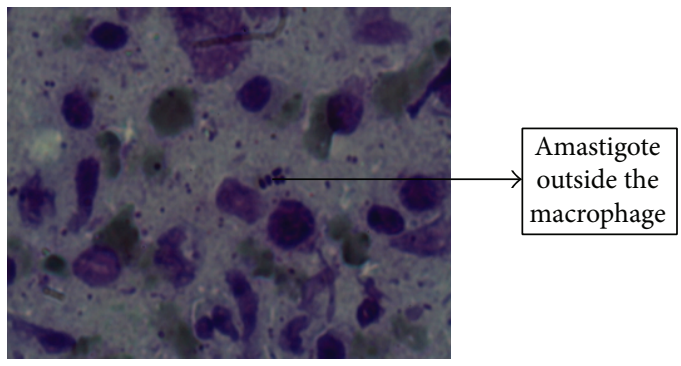

FIGURE 3: Giemsa stain image showing the amastigote form of Leishmania outside macrophages.

Molecular characterization of Leishmania species which cause cutaneous leishmaniasis in Kohat, Khyber Pakhtunkhwa, was reported in the present study. Sporadicalness of CL is reported in other parts of Pakistan, Afghanistan, India, and Iran where both $L$. tropica and $L$. donovani were found to cause leishmaniasis in particular areas $[8,19] . \mathrm{CL}$ is prevalent in Pakistan and reported from all the provinces $[16,20]$ where the causative agent is Leishmania tropica $[17,21]$.

Our study revealed that $L$. tropica was the sole causative agent for cutaneous leishmaniasis which was examined in all cases in the endemic region in Kohat of Khyber Pakhtunkhwa. Out of 113 cases studied most belonged to a poor socioeconomic class, living in rural and hilly tract areas. The infection was more common in female than in male, which is in contrast to the report of $[22,23]$ and this may be due to ecological, cultural, environmental, and socioeconomic conditions of the areas. The finding of the present study was similar to the report of $[8,16]$.

This study emphasized diagnosis and species identification in a large number of patients with $\mathrm{CL}$ in the regions of 


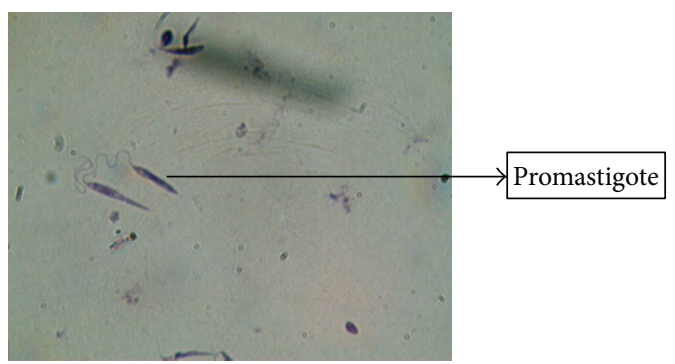

FIGURE 4: Giemsa stain image showing the promastigotes form of Leishmania in RPMI culture media.

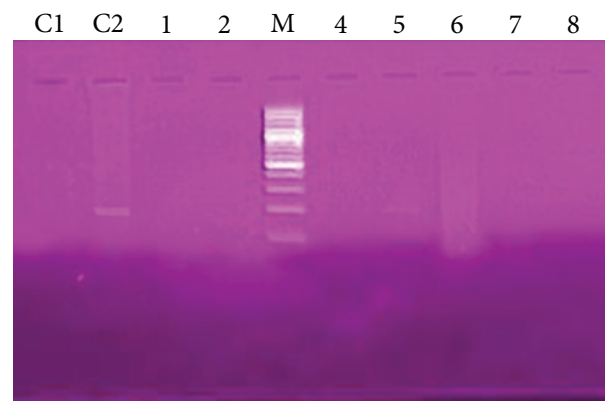

FIGURE 5: M: marker $100 \mathrm{bp}, \mathrm{C1}$ : negative control, C2: positive control, and 5: positive sample showing $186 \mathrm{bp}$.

TABLE 3: Result showing the sensitivity and specificity of PCR, microscopy, and culture diagnostic methods.

\begin{tabular}{lccc}
\hline Serial number & Methods & Sensitivity & Specificity \\
\hline 1 & PCR & $87.61 \%$ & $12.38 \%$ \\
2 & Microscopy & $53.98 \%$ & $46.0 \%$ \\
3 & Culture & $46.90 \%$ & $53.09 \%$ \\
\hline
\end{tabular}

Kohat, and it was identified the L. tropica is the etiological agent of the infection. The kDNA PCR was the most accurate diagnostic assay and was recognized as the most reliable method in the diagnosis of CL. The test may be standardized for the detection of parasite in patients of CL having negative microscopic examination and/or culture results. For the vitro culture and direct microscopic diagnosis a high number of amastigotes of CL are required which is very low in skin lesions [20, 23].

As in the specified region there is no facility for culture only diagnosis and detection of Leishmaniasis are based on direct microscopy which is easy and cheap with low accuracy even if carried out by skilled persons [24, 25]. While PCR is more sensitive, and specific than conventional methods in term of the diagnosis of the cutaneous leishmaniasis [8, $20]$. So in the present study, culture showed $46.90 \%$ (53/113) sensitivity and direct microscopy with smear biopsies showed 68.14\% (61/113) sensitivity, whereas PCR 87.61\% (99/113) sensitivity which is more sensitive in diagnosis of the disease. Similarly tissue smears $(37 \%-60 \%)$ and culture 38 percent results have been shown in CL in India and in the nearer countries of Pakistan [19, 26].

\section{Conflict of Interests}

The authors declare that there is no conflict of interests regarding the publication of this paper.

\section{Acknowledgment}

The authors are thankful to the Deanship of Scientific Research King Saud University for funding the work through the research Group Project no. RGP-VPP-210.

\section{References}

[1] B. L. Herwaldt, "Leishmaniasis," The Lancet, vol. 354, no. 9185, pp. 1191-1199, 1999.

[2] H. W. Murray, J. D. Berman, C. R. Davies, and N. G. Saravia, "Advances in leishmaniasis," The Lancet, vol. 366, no. 9496, pp. 1561-1577, 2005.

[3] WHO, The World Health Report. Changing History, WHO, Geneva, Switzerland, 2004.

[4] J. Berman, "Current treatment approaches to leishmaniasis," Current Opinion in Infectious Diseases, vol. 16, no. 5, pp. 397401, 2003.

[5] N. Ali and F. Afrin, "Protection of mice against visceral leishmaniasis by immunization with promastigote antigen incorporated in liposomes," Journal of Parasitology, vol. 83, no. 1, pp. 70-75, 1997.

[6] N. Hepburn, "Cutaneous leishmaniasis. Part II: historical aspects, epidemiology and prevention," Proceedings of the Royal College of Physicians of Edinburgh, vol. 23, no. 2, pp. 140-150, 1993.

[7] A. M. Bhutto, R. A. Soomro, S. Nonaka, and Y. Hashiguchi, "Detection of new endemic areas of cutaneous leishmaniasis in Pakistan: a 6-year study," International Journal of Dermatology, vol. 42, no. 7, pp. 543-548, 2003.

[8] S. Ayaz, S. Khan, S. N. Khan et al., "Cutaneous leishmaniasis in Karak, Pakistan: report of an outbreak and comparison of diagnostic techniques," African Journal of Biotechnology, vol. 10, no. 48, pp. 9908-9910, 2011.

[9] W. H. Markle and K. Makhoul, "Cutaneous leishmaniasis: recognition and treatment," American Family Physician, vol. 69, no. 6, pp. 1455-1460, 2004.

[10] P. Desjeux, "Leishmaniasis: current situation and new perspectives," Comparative Immunology, Microbiology and Infectious Diseases, vol. 27, no. 5, pp. 305-318, 2004.

[11] S. Ajdary, M. H. Alimohammadian, M. B. Eslami, K. Kemp, and A. Kharazmi, "Comparison of the immune profile of nonhealing cutaneous leishmaniasis patients with those with active lesions and those who have recovered from infection," Infection and Immunity, vol. 68, no. 4, pp. 1760-1764, 2000.

[12] G. Schönian, I. Mauricio, M. Gramiccia, C. Cañavate, M. Boelaert, and J.-C. Dujardin, "Leishmaniases in the Mediterranean in the era of molecular epidemiology," Trends in Parasitology, vol. 24, no. 3, pp. 135-142, 2008.

[13] A.-L. Bañuls, F. Guerrini, F. Le Pont et al., "Evidence for hybridization by multilocus enzyme electrophoresis and random amplified polymorphic DNA between Leishmania braziliensis and Leishmania panamensis/guyanensis in Ecuador," Journal of Eukaryotic Microbiology, vol. 44, no. 5, pp. 408-411, 1997. 
[14] I. L. Mauricio, J. R. Stothard, and M. A. Miles, "Leishmania donovani complex: genotyping with the ribosomal internal transcribed spacer and the mini-exon," Parasitology, vol. 128, no. 3, pp. 263-267, 2004.

[15] A. Nasereddin, E. Bensoussan-Hermano, G. Schönian, G. Baneth, and C. L. Jaffe, "Molecular diagnosis of old world cutaneous leishmaniasis and species identification by use of a reverse line blot hybridization assay," Journal of Clinical Microbiology, vol. 46, no. 9, pp. 2848-2855, 2008.

[16] J. D. Marco, A. M. Bhutto, F. R. Soomro et al., "Multilocus enzyme electrophoresis and cytochrome B gene sequencingbased identification of Leishmania isolates from different foci of cutaneous leishmaniasis in Pakistan," American Journal of Tropical Medicine and Hygiene, vol. 75, no. 2, pp. 261-266, 2006.

[17] K. Katakura, "Molecular epidemiology of leishmaniasis in Asia (focus on cutaneous infections)," Current Opinion in Infectious Diseases, vol. 22, no. 2, pp. 126-130, 2009.

[18] S. Rahman, F. H. Abdullah, and J. A. Khan, "The frequency of old world cutaneous leishmaniasis in skin ulcers in Peshawar," Journal of Ayub Medical College, Abbottabad, vol. 21, no. 3, pp. 72-75, 2009.

[19] N. L. Sharma, V. K. Mahajan, A. Kanga et al., "Localized cutaneous leishmaniasis due to Leishmania donovani and Leishmania tropica: preliminary findings of the study of 161 new cases from a new endemic focus in Himachal Pradesh, India," American Journal of Tropical Medicine and Hygiene, vol. 72, no. 6, pp. 819-824, 2005.

[20] M. Kassi, M. Kassi, A. K. Afghan, R. Rehman, and P. M. Kasi, "Marring leishmaniasis: the stigmatization and the impact of cutaneous leishmaniasis in Pakistan and Afghanistan," PLoS Neglected Tropical Diseases, vol. 2, no. 10, article e259, 2008.

[21] H. Amtul and S. Shaheen, "Laboratory diagnosis of leishmaniasis by PCR," in Souvenir of 3rd Annual Hamdard Symposium, p. $18,2001$.

[22] S. K. Agarwal, V. S. Chadda, and S. K. Agarwal, "A study of epidemiology of human cutaneous Leishmaniasis in Bikaner (Rajasthan)," Indian Journal of Dermatology, Venereology and Leprology, vol. 47, no. 6, pp. 303-306, 1981.

[23] D. K. Kochar, S. Aseri, B. V. Sharma, R. A. Bumb, R. D. Mehta, and S. K. Purohit, "The role of rifampicin in the management of cutaneous leishmaniasis," QJM, vol. 93, no. 11, pp. 733-737, 2000.

[24] M. Lopez, R. Inga, M. Cangalaya et al., "Diagnosis of Leishmania using the polymerase chain reaction: a simplified procedure for field work," American Journal of Tropical Medicine and Hygiene, vol. 49, no. 3, pp. 348-356, 1993.

[25] N. Rodriguez, B. Guzman, A. Rodas, H. Takiff, B. R. Bloom, and J. Convit, "Diagnosis of cutaneous Leishmaniasis and species discrimination of parasites by PCR and hybridization," Journal of Clinical Microbiology, vol. 32, no. 9, pp. 2246-2252, 1994.

[26] J. Dogra, N. Aneja, B. B. Lal, and S. N. Mishra, "Cutaneous leishmaniasis in India: clinical experience with itraconazole (R51 211 janssen)," International Journal of Dermatology, vol. 29, no. 9, pp. 661-662, 1990. 


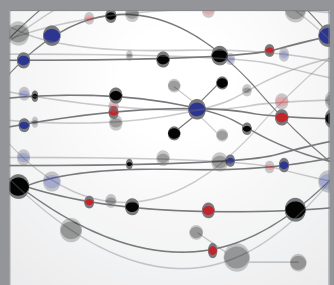

The Scientific World Journal
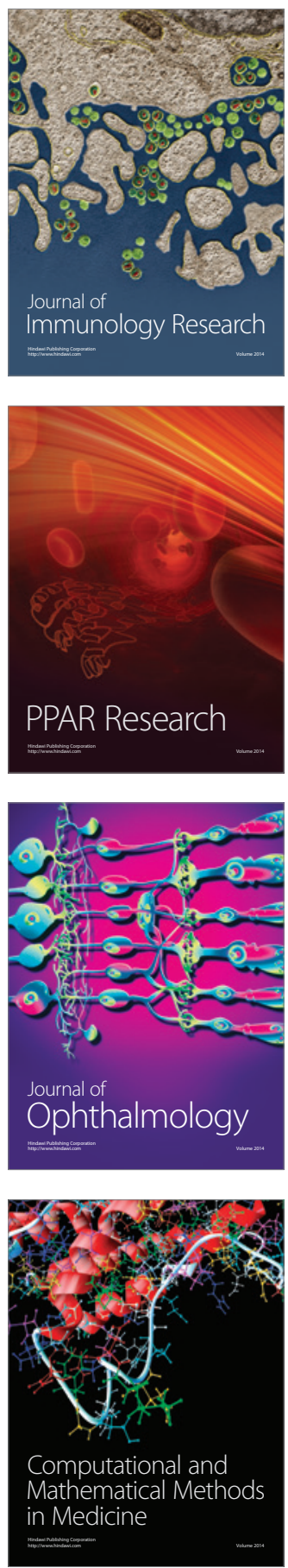

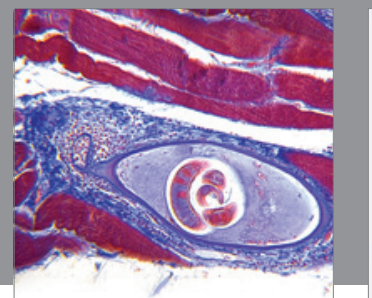

Gastroenterology

Research and Practice
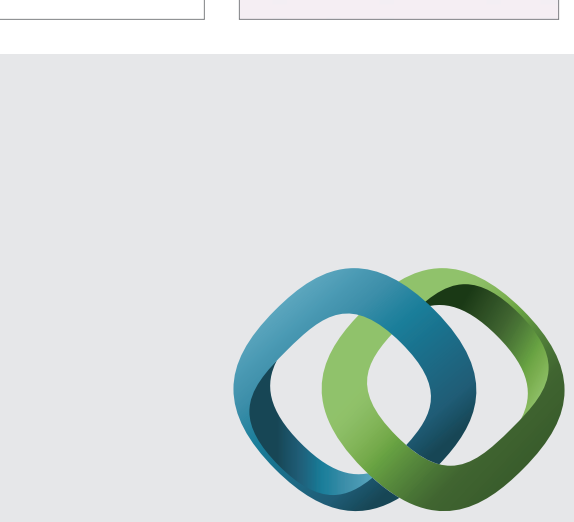

\section{Hindawi}

Submit your manuscripts at

http://www.hindawi.com
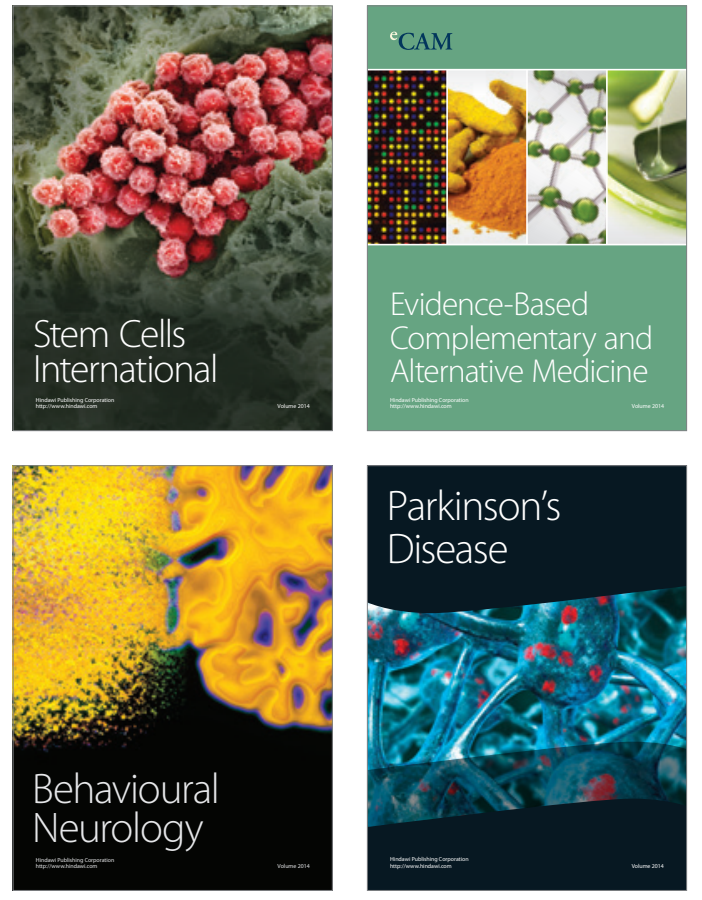
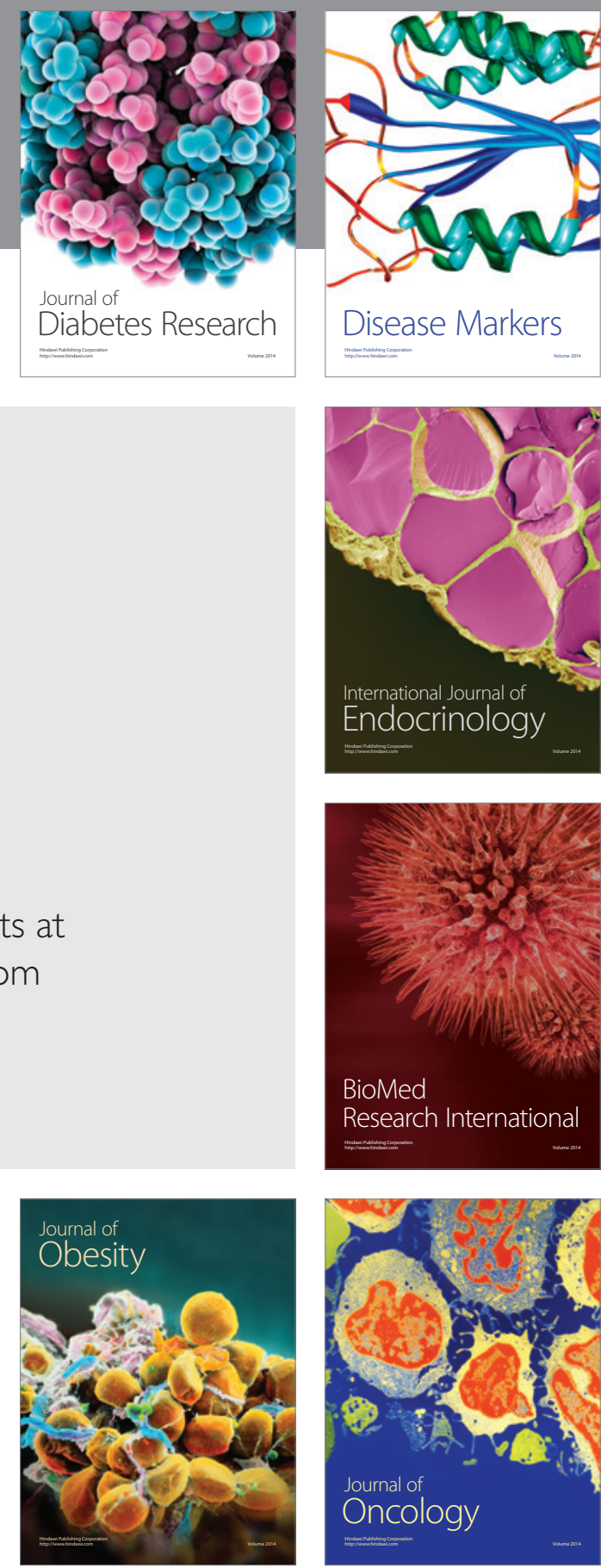

Disease Markers
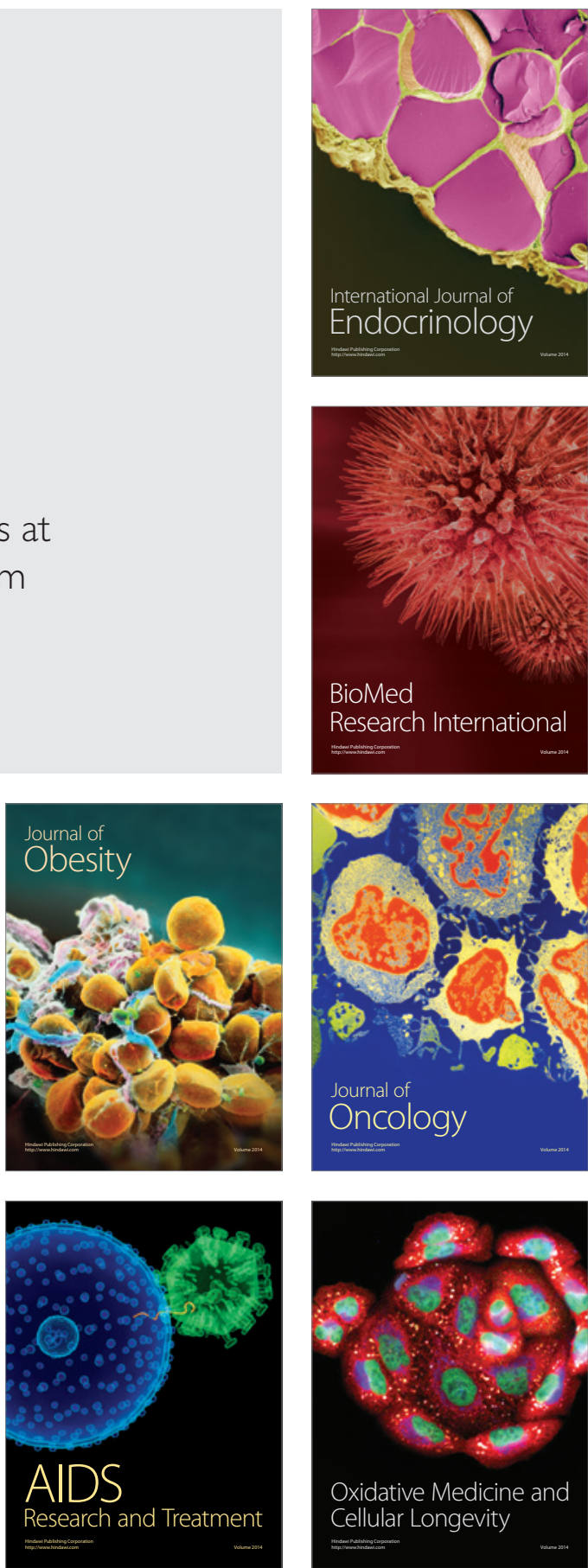